\title{
Generation Forecasting Models for Wind and Solar Power
}

\author{
Sonali N. Kulkarni ${ }^{1 *}$, Prashant Shingare ${ }^{2}$ \\ 1 Research Scholar, Electronics \& Telecom Engineering, University of Mumbai, Rajiv Gandhi Institute of \\ Technology, Versova, Andheri (W), Mumbai, Maharashtra, 400053 India. \\ ${ }^{2}$ Director of Renewable Energy, Vertiv Energy Pvt. Ltd, NITCO Business Park, Wagle Industrial Estate, Thane \\ (W), Maharashtra, 400604 India.
}

* Corresponding author. Tel.: +1 952687 0995; email: ksonali2006@gmail.com

Manuscript submitted June 10, 2018; accepted August 3, 2018.

doi: 10.17706/ijcee.2018.10.4.318-329

\begin{abstract}
Over the past three decades power demand has increased remarkably due to industrialization and increased demand of automation. On the other hand conventional energy sources like fossil fuel are ever depleting. Therefore, industry and scientist are focusing on renewable energy (RE) sources like wind, solar etc., to address twin challenge of energy security and reduction in pollution caused by excessive fossil fuel usage. Further, number of consumers generating renewable energy in distributed manner and participating in the power network is increasing drastically. This exponential rise in penetration of renewable energy into existing power system has posed challenges to grid stability, reliability and power quality. A precise power demand-generation balance is challenging in smooth and reliable operation network, irrespective of unpredictable demand and intermittent nature of renewable power generation. In this research paper we have discussed and designed time series generation forecast models for wind and solar using historical RE generation data for Maharashtra state of India. Forecast results of designed solar and wind power generation models are compared. The wind and solar power generation forecasts obtained in this paper will help the power system operators; while taking decisions related to energy mix, generation planning, scheduling to maintain reliable and economical operation of power system.
\end{abstract}

Key words: Demand supply balance, forecast error, power quality, renewable energy generation forecasting, smart grid, statistical techniques.

\section{Introduction}

Over the past three decades, global energy generation and consumption have accelerated to unprecedented degrees. In India; every day a large amount of electricity is used for residential, commercial, industrial process applications and automation. The demand for renewable energy (RE) sources like wind, solar, biogas etc. for power generation increased significantly due to lack of conventional energy sources, environmental issues and rise in the cost of fossil fuels. Among the various renewable energy sources solar, small hydro power and wind are having potential to provide solution to increasing power demand [1]. Most of the renewable energy sources are highly intermittent in nature, have limited capacity, and are installed in a more distributed manner. From literature it is observed that among the renewable power generation sources, wind and solar generation are the fastest growing energy sources in the world, as they are clean, non-polluting and it does not produce any byproducts harmful to the environment. Although, various modern solar and wind power generation techniques are being used for power generation, the generated power is highly intermittent due to variable nature of natural resources. Therefore it is necessary to study 
and understand their characteristics before integrating renewable generators to the grid [1]-[4]. The intermittent and unpredictable renewable energy generation coupled with varying nature of load causes demand-supply mismatch, impacting grid stability [1], [5], [7], [8]. Short term renewable power generation forecasting is essential to power system operators in taking decisions related to energy mix, power purchase, load switching and conventional power generation planning and scheduling in order to maintain the balance between demand and generation [8], [9]. Therefore, power system operators rely on generation forecasting so that optimum generation can be achieved in order to maintain healthy power quality, reliability in an economic sense [7], [8].

In this paper, we have discussed and designed statistical time series models using an innovative method for wind and solar power generation data collected from Load Dispatch Center (LDC) of Maharashtra state in India, to forecast short term renewable power generation. Further the forecast results of newly designed model for wind and solar are compared with traditional one, on the basis of different performance parameters. The models discussed in this paper will be useful to LDC centers across the India and power management system operators while taking important decisions related to their day to day operations.

This paper is organized as follows: Section 2 reviews the need and types of power generation forecasting. Section 3 describes the commonly used performance parameters to evaluate accuracy of forecast results. Wind and solar power generation forecasting methods, their mathematical model's results are presented in Section 4, followed by conclusion.

\section{Generation Forecasting}

\subsection{Need for Renewable Power Generation Forecasting}

With high penetration of renewable energy like wind, solar etc, in distribution network, the power sector is concerned about the stability of utility grid, power quality (PQ) and voltage regulation [4], [5]. The variation in power quality parameters of grid like voltage, frequency, harmonic distortion, noise etc., leads to poor power quality and grid instability [1], [5], [7], [10]. The stability, reliability and power quality of power system is highly dependent on variable nature of power demand, power generation and transmission line limitations. The issues of power quality are of importance to wind energy generators as compared to solar, because individual wind generation unit is of large capacity up to few Megawatts. Further, such a large capacity wind power generator is feeding into distribution circuits, with customers connected in close proximity [8]-[11]. Irrespective of introduction of special grid codes for integration of RE power and technological developments in wind turbine generator technology like Doubly Feed Induction Generators (DFIG); Hybrid Direct Drive (HDD), the fluctuations in wind speed have a negative impact on power generation, hence on stability and power quality of power system [1], [3], [8], [11].

Power generation forecasting is a process of prediction of power generation of different renewable generators by analyzing the historical power generation data. The power generated by renewable power generators like wind and solar offers alternative sources of energy, which are in general pollution free, technologically effective, environmentally sustainable and provides electricity without giving rise to carbon dioxide emissions [1], [2], [7], [8], [11]. But power generated by renewable sources like wind and solar is intermittent in nature and highly dependent on the availability of natural resources [1]-[5]. Therefore historical information of hourly, daily, weekly, monthly, and yearly power generation data is analyzed to determine generation forecast [12]. The accurate information related to power generation forecasting is needed due to following reasons:

- Accurate generation forecasting helps power system operator in planning operation of electric power systems smoothly. It is necessary to maintain balance between demand and generation in order to maintain required grid frequency and hence power quality [5], [7], [8], [13]. 
- It helps power system operator in making important decisions related to power purchase, generation scheduling, fuel allocation, loads switching etc., by considering infrastructural limitations [14].

- Power generation forecasting is important factor in economical operation of power companies [10]. The accurate power generation forecasting helps in operational and maintenance cost savings as forecasting error, both positive and negative, results into increased operational cost of power network [15], [16].

- Power generated by renewable energy sources is intermittent and unpredictable in nature whereas the power demand is also changing from time to time [1], [5], [11], [12]. Over and above, changes in weather conditions like temperature, and humidity increases the complexity in demand supply balance [12].

\subsection{Difficulties in Power Demand- Supply Balance}

For smooth functioning of conventional grid or smart grid, it is very import but crucial to maintain balance between demand and generation. However, exact estimation of power demand is extremely complicated as it involves various uncertainties. Power demand shows following characteristics [12]-[17]:

- Power demand of various customers varies from time to time and frequency of variation is high

- Demand is non-schedulable

- It has non constant mean and variance (non stationary series)

- Multiple seasonality: Fig. 1 shows variation in maximum power demand for Maharashtra state of India during a particular week. It is observed that power demand on weekends and holidays is different than weekdays; it also varies with month, week and day of a week etc.

\section{Daily Maximum Power Demand}

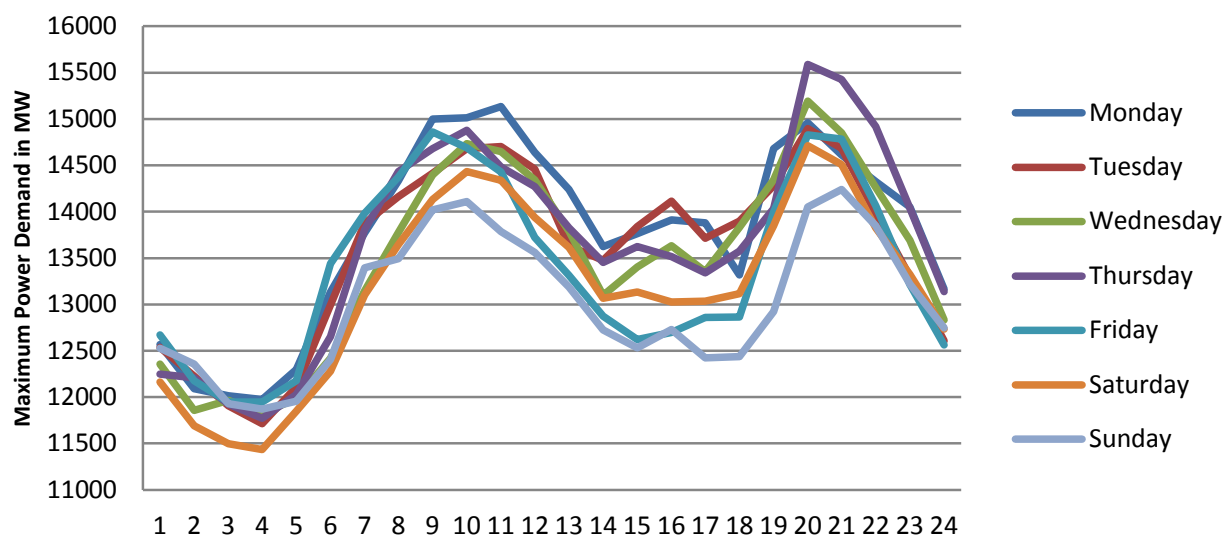

Fig. 1. Hourly Power Demand (in MW) on different days in a week [18].

Following difficulties are faced at generator side, while maintaining demand supply balance:

- The power generated by conventional generators varies with availability of resources.

- Power generated by renewable energy sources like wind and solar is intermittent and varies from time to time. An obvious reason for intermittent variation of RE power is availability of natural resources [1], [8], [11]. Fig. 2 shows variation in solar and wind power generation during a particular week. 

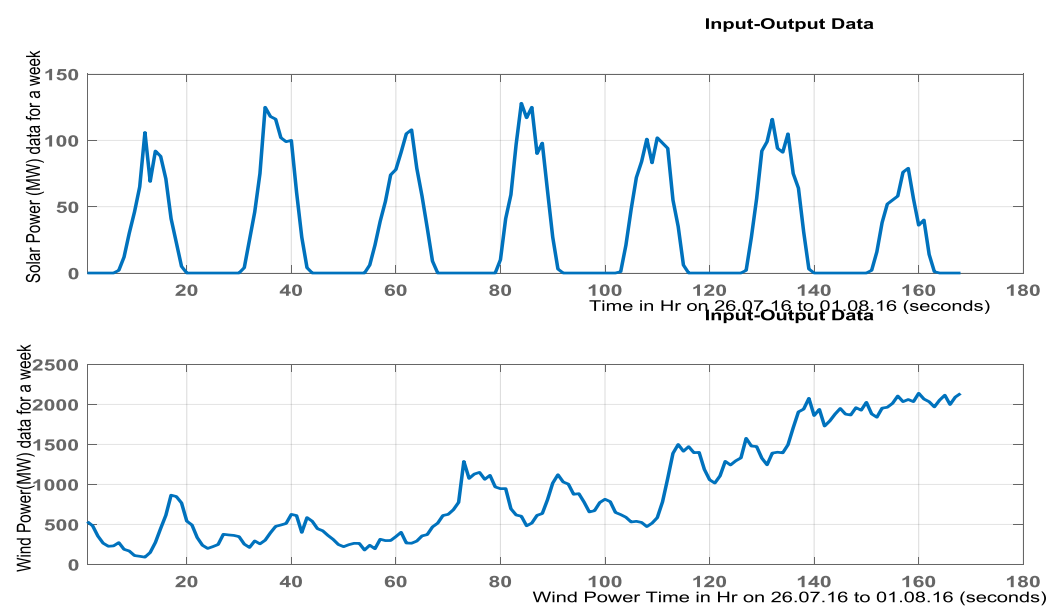

Fig. 2. Hourly solar and wind power generation (MW) in a week [18].

\subsection{Types of Generation Forecasting}

Power generation forecasting methods are classified on the basis of duration of forecasting. They are broadly classified into four types [19], [20], as in Table 1. Out of all these methods, short term generation forecasting is very important in smooth operation of power system and utility [21]. Short term generation forecasting with time lead of one to three hour is mainly needed for real time control, generation planning, scheduling while taking decisions related to energy mix, at various load dispatch centers across India.

Table 1. Generation Forecasting Types [19], [20]

\begin{tabular}{|l|l|l|}
\hline $\begin{array}{l}\text { Type of Generation } \\
\text { Forecasting }\end{array}$ & Forecasting Duration & Application \\
\hline Very Short Term & Few Minutes to an Hour & Real time grid operations, regulations and control etc. \\
\hline Short Term & Few Hours to a Few Weeks & $\begin{array}{l}\text { Scheduling of generation planning, short term } \\
\text { maintenance and power purchase etc. }\end{array}$ \\
\hline Medium Term & $\begin{array}{l}\text { Few Months to Five Years } \\
\text { Prior to Actual Requirement }\end{array}$ & $\begin{array}{l}\text { Planning Utilities, maintenance scheduling and } \\
\text { coordination of power sharing etc. }\end{array}$ \\
\hline Long Term & Twenty Years in Advance & $\begin{array}{l}\text { Capacity planning for economical operation of power } \\
\text { system and regulatory policy etc. }\end{array}$ \\
\hline
\end{tabular}

\section{Forecast Accuracy}

The various useful and popular techniques are being used by researchers for forecasting renewable power generation. In most of the forecasting techniques, models are designed using the open source historical power generation data and tested by applying some real time or simulated time series data. The estimated forecast results of different models are compared on the basis of various performance parameters to determine forecast accuracy [22], [23]. These are known as performance metrics. Each of these parameter is a function of actual values and its forecasted value in a given time series. In the following definitions, $Y_{t}$ is the actual value, $F_{t}$ is forecasted value, forecast error is referred as $\mathrm{FE}=Y_{t}-F_{t}$, and $\mathrm{n}$ is size of the test set.

\subsection{The Mean Forecast Error (MFE)}

MFE is a measure of the average deviation of forecasted values from actual ones. It is given as in (1) [24],

$$
\operatorname{MFE}=1 / \mathrm{n} \sum_{t=1}^{\mathrm{n}}\left(Y_{t}-F_{t}\right)
$$


where $\mathrm{n}$ is number of forecasts. For a good forecast value of MFE should be as small as possible. Its features are:

- It is known as forecast bias. It shows direction of error but does not penalize extreme errors.

- A zero MFE does not mean that forecasts are perfect as effects of positive and negative errors cancel out.

\subsection{The Mean Absolute Forecast Error (MAFE)}

MAFE is a measure of average absolute deviation of forecasted values from actual value. It is given in (2) [22], [24], [25]

$$
\mathrm{MFE}=\frac{1}{\mathrm{n} \sum_{t=1}^{\mathrm{n}}\left|Y_{t}-F_{t}\right|}
$$

It is the magnitude of error occurred during forecasting. It is also known as Mean Absolute Deviation (MAD). Its features are:

- In MAFE, the effects of positive and negative error do not cancel out. It depends on the scale of measurement and data transformation.

- For a good forecast, the value of MAFE should be as small as possible.t

- MAFE does not panelize extreme forecast errors.

\subsection{The Mean Absolute Percentage Error (MAPE)}

MAPE represents the percentage of mean absolute percentage error observed. It is calculated using (3) [24]-[26]:

$$
\operatorname{MAPE}=1 / \mathrm{n} \sum_{t=1}^{\mathrm{n}}\left|\frac{\mathrm{FE}}{Y_{t}}\right| * 100
$$

It's important features are:

- It does not show the direction of error.

- In this measure, opposite signed errors do not cancel each other.

- It does not get affected by scale of measurement, but by data transformation.

\subsection{The Mean Squared Error (MSE):}

MSE is a measure of average squared forecast error. It is defined in (4) as [26], [27],

$$
\operatorname{MSE}=1 / \mathrm{n} \sum_{t=1}^{\mathrm{n}} \mathrm{FE}^{2}
$$

Its features are

- In MSE, opposite signed errors do not cancel each other. It gives overall error occurred during forecasting but does not provide any idea about the direction of error.

- It panelizes extreme error occurred while forecasting.

- MSE gets affected by large errors than small errors.

- It is sensitive to data transformations or change of scale.

\section{Short Term Generation Forecasting Methods and Model Results}

A large variety of statistical and artificial intelligence techniques are used for short-term RE generation forecasting. For the short term RE generation forecasting different methods like Statistical Methods, Auto 
Regression, Similar Day Approach, Artificial Neural Network (ANN), Expert Systems are used [16]. While forecasting short-term RE power generation, several factors like time, weather data etc are considered. The time factors consider time of the year, day of the week, and hour of the day as the power generation varies with the above factor. Time series analysis is a statistical approach of forecasting. The time series data has attracted many scientists and researchers over last few decades. Time series forecasting methods are used in numerous fields like business, finance, science and engineering to determine future values [22]-[27].The main aim of time series modeling is to study the past available time series data to develop the appropriate model. Statistical approach for short term RE generation forecasting require a mathematical model that represents forecast as a function of different factors such as time, weather condition etc.. This model is then used to generate future values for the time series or to make forecast. Time series forecasting is an act of predicting the future by understanding the past [10]-[24]. A proper care is required to be taken to fit an adequate model to the available time series data. A lot of efforts have been taken by researchers for the development of efficient models to improve forecast accuracy. The various important time series forecasting models are defined in literature.

The two important categories of statistical mathematical models are: additive models and multiplicative models [10]-[24]. They differ depending upon the load forecast is the addition or sum of a number of components or the product or multiplication of a number of factors. The additive model designed for predicting load is function of four components and is given in (5),

$$
L=L_{n}+L_{w}+L_{s}+L_{r}
$$

where $L$ is the total load, $L_{n}$ represents the "normal" part of load, it is a set of standardized forecast for each "type" of day that has been identified as occurring throughout the year, $L_{w}$ is weather sensitive part of load, $L_{s}$ is a special event component which create a deviation in generation from usual load pattern, and $L_{r}$ is a completely random term, called as noise [10]-[24]. The multiplicative model is given by (6),

$$
L=L_{n} * F_{w} * F_{S} * F_{r}
$$

where $L_{n}$ is normal or base value of generation and $F_{w}, F_{s}$ and $F_{r}$ are correction factors that affect overall generation. The correction factors $F_{w}, F_{s}$ and $F_{r}$ are positive numbers based on weather $\left(F_{w}\right)$, special events $\left(F_{s}\right)$, and random fluctuation $\left(F_{r}\right)$. Sometimes factors like pricing $\left(F_{p}\right)$ and generation growth $\left(F_{g}\right)$ are also considered. The decomposition of time series is based on four components: trend, cyclic, seasonal and trend components. In order to find the accurate RE power generation forecast the impact of each component on time series need to be identified [10]-[25]. The following sections describe the model design procedure and the comparison of model results.

\subsection{Steps in Time Series Model Design Process}

In this paper we have used statistical approach to analyze open source RE power generation data, specifically wind and solar generation data of load dispatch center of Maharashtra state in India. We have analyzed time series data to design the model and the designed model is used for forecasting. The procedure followed for designing ARIMA ( $p$ d q) model for power generation forecast are given in Fig. 3. As shown in Fig. 3, initially we have collected selected, preprocessed raw data and autocorrelation (ACF) plot is taken. By observing ACF plot it is possible to identify whether time series is non stationary or stationary and which model is suitable. If time series is stationary then ARMA(p q) model is used and if not ARIMA(p d q) model is suitable. Then partial autocorrelation (PACF) is taken. The order of ARIMA(p $d$ q) model is obtained by observing ACF and PACF plot. In our work, by observing ACF and PACF plot of preprocessed RE power generation data, it is noticed that for wind and solar power generation $\operatorname{ARMA}(p \mathrm{q})$ model is suitable. 


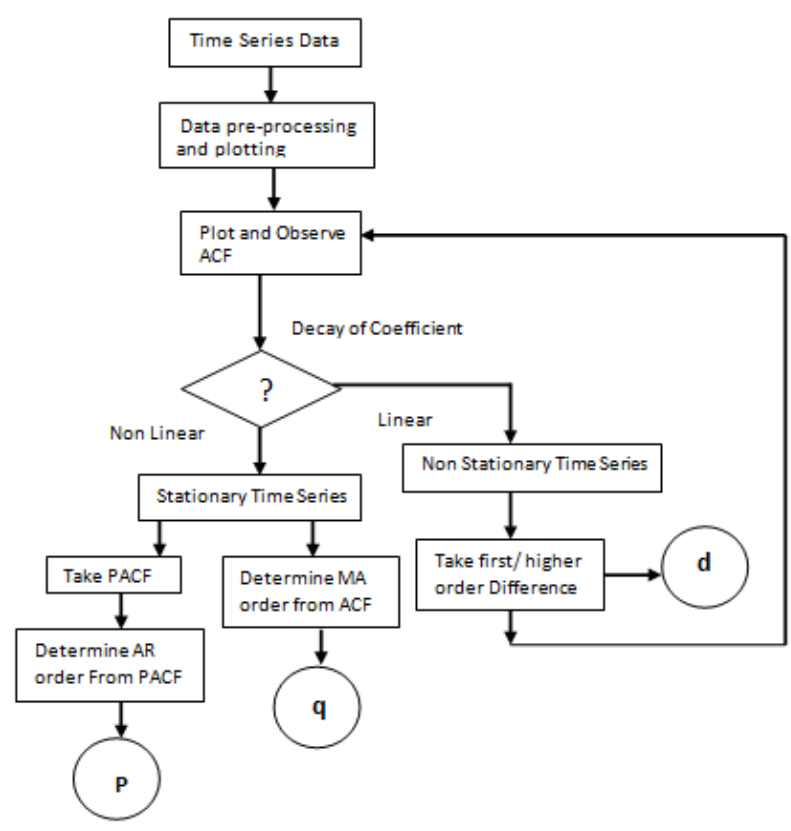

Fig. 3. Steps in ARIMA(p d q) model design process.

\subsection{Auto Regressive Moving Average (ARMA(p q)) Method}

Auto Regressive Moving Average (ARMA(p q)) on is one of the most widely used statistical techniques. The expression for output, $Y(t)$ is given in (7) [10], [26], [27].

$$
Y(t)=\sum_{k=1}^{p} \emptyset k * y(t-k)+a(t)+\sum_{j=1}^{q} b j * e(t-j)
$$

First term corresponds to autoregressive process of order $p$ and $\emptyset k$ is known as coefficient of delay polynomial. In autoregressive process $A R(\mathrm{p})$, the current value of the time series $Y(t)$ is expressed linearly in terms of its previous values like $[y(t-1), y(t-2), \ldots . . y(t-p)]$ and coefficient of delay polynomial $\emptyset p$. The second term is a random noise $a(t)$ and third term corresponds to moving average $M A(q)$ process of order $q$.

The solar power generation data of Maharashtra state of India is used to design forecast model using the procedure discussed in Section 4.1. ARMA(p q) model is designed using Excel and Matlab (R2016b). The comparison of forecast results of two models ARMA (1 24) and ARMA (7 25) with actual solar power generation values is shown in Fig. 4.

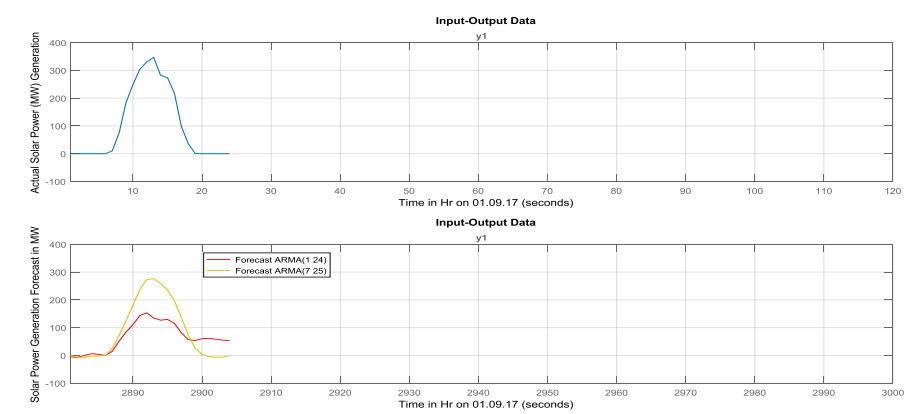

Fig. 4. Actual solar power generation data [18], forecast results of ARMA(1 24), ARMA(7 25) for 24 hour.

Further, ARMA(p q) models are designed using the procedure discussed in Section 4.1 for historical wind 
power generation data for Maharashtra state of India. The wind power generation forecast results of three ARMA models for different time horizon are shown in Fig. 5 and the comparison of forecasts on the basis of different parameters as shown in Table 2 .
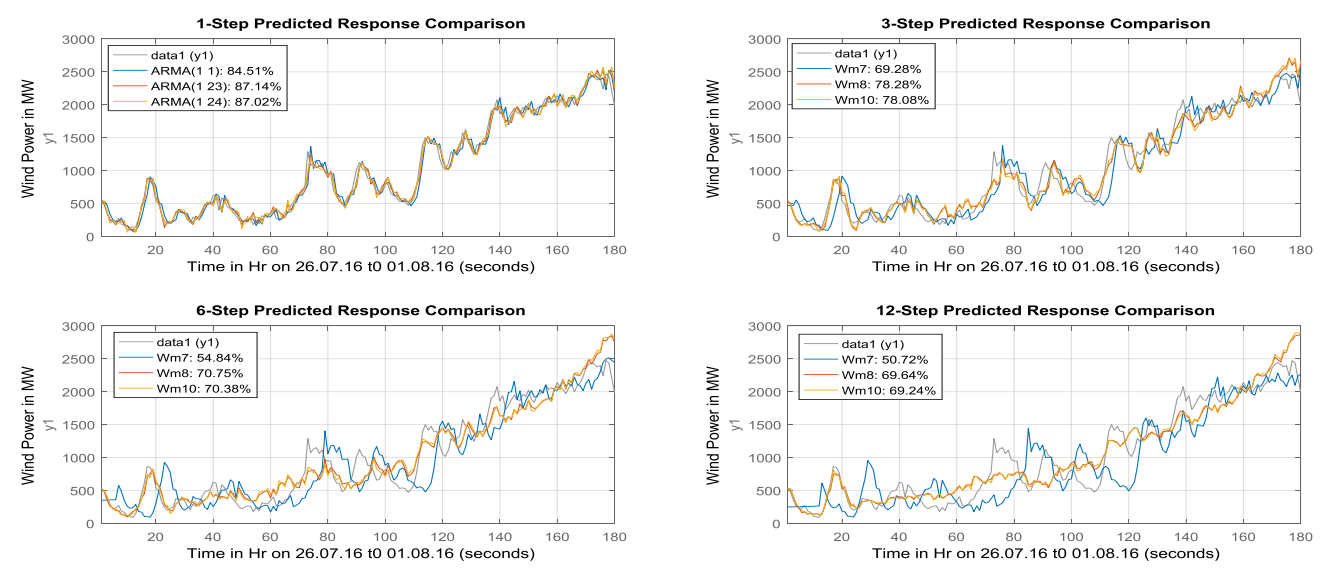

Fig. 5. Model results of wind ARMA(1 1), ARMA(1 23), ARMA(1 24) for different prediction horizons.

Similarly, solar power generation data of load dispatch centre of Maharashtra state in India is used to design different models. The results of models for different time horizons are shown in Fig. 6 and model forecasts are compared on the basis of different performance parameters as in Table 3.

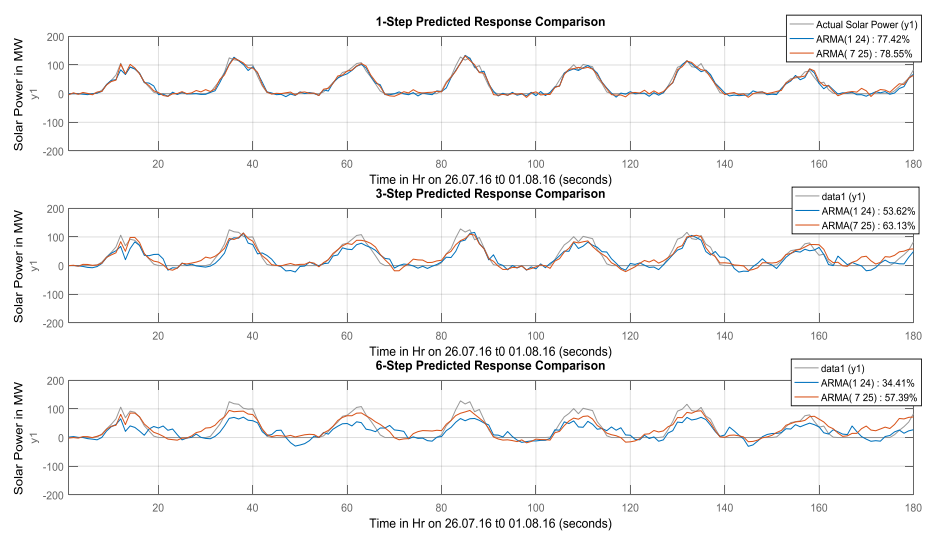

Fig. 6. Model results of solar ARMA(1 24), ARMA(7 25) for different prediction horizons.

\subsection{Hybrid ARMA(p q) Model}

In this work we have designed innovative method, named Hybrid ARMA(p q) to forecast wind and solar power generation. In hybrid ARMA model, the time series data is processed again and all steps defined in Section 4.1 is used to design model. In hybrid ARMA process preprocessed series, $Y^{\prime}(t n)$ is applied as input to integrated autoregressive moving average process. The series $Y^{\prime}(t n)$ on any date " $d$ " is determined using (8) as [15], [22], [24]:

$$
Y^{\prime}(t n)=[y(t n) d-1+y(t n) d-2+y(t n) d-3] / 3
$$

where $n=1,2,3,4, \ldots .24$ and $d=1,2,3 \ldots . .31$. The output $Y(t)$ of hybrid ARMA process is given by

$$
Y(t)=\sum_{k=1}^{p} \emptyset k * y^{\prime}(t n-k)+a(t)+\sum_{j=1}^{q} b j * e^{\prime}(t n-j)
$$


where

$$
\begin{aligned}
y^{\prime}(t n-1) & =[y(t n-1) d-1+y(t n-1) d-2+y(t n-1) d-3] / 3 \\
y^{\prime}(t n-2) & =[y(t n-2) d-1+y(t n-2) d-2+y(t n-2) d-3] / 3 \\
y^{\prime}(t n-p) & =[y(t n-p) d-1+y(t n-p) d-2+y(t n-p) d-3] / 3
\end{aligned}
$$

In our work, preprocessing of historical wind and solar power generation data is carried out using Excel as it offer very good flexibility and Matlab (R2016b) is used for Hybrid ARMA(p q) model design. The wind power forecast results of designed hybrid ARMA_H-3(1 1), ARMA_H-3(2 1) and ARMA_H-7(1 1) models for different time horizon are given in Fig. 7 and comparison of forecast results with ARMA model are given in Table 2.
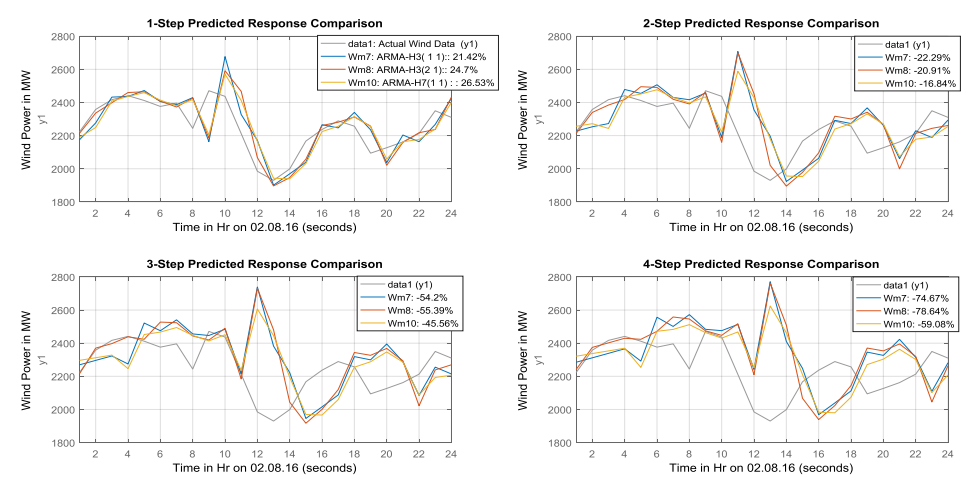

Fig. 7. Wind power generation forecast ARMA_H3(1 1),ARMA_H3(1 2) and ARMA_H7(1 1) for different horizons.

Table 2. Comparison of ARMA_H and ARMA Models for Wind Power Generation

\begin{tabular}{|llll||}
\hline Model/ Parameters & Fit to Estimation & Forecast Prediction Error & Mean Square Error \\
ARMA(1 1) & $82.99 \%$ & 12040 & 11620 \\
ARMA(1 23) & $86.80 \%$ & 12440 & 7000 \\
ARMA(1 24) & $86.93 \%$ & 12510 & 6859 \\
ARMA-H3(1 1) & $73.55 \%$ & 4402 & 3424 \\
ARMA-H3(1 2) & $75.10 \%$ & 4629 & 3033 \\
ARMA-H7(1 1) & $65.77 \%$ & 3375 & 2625 \\
\hline
\end{tabular}
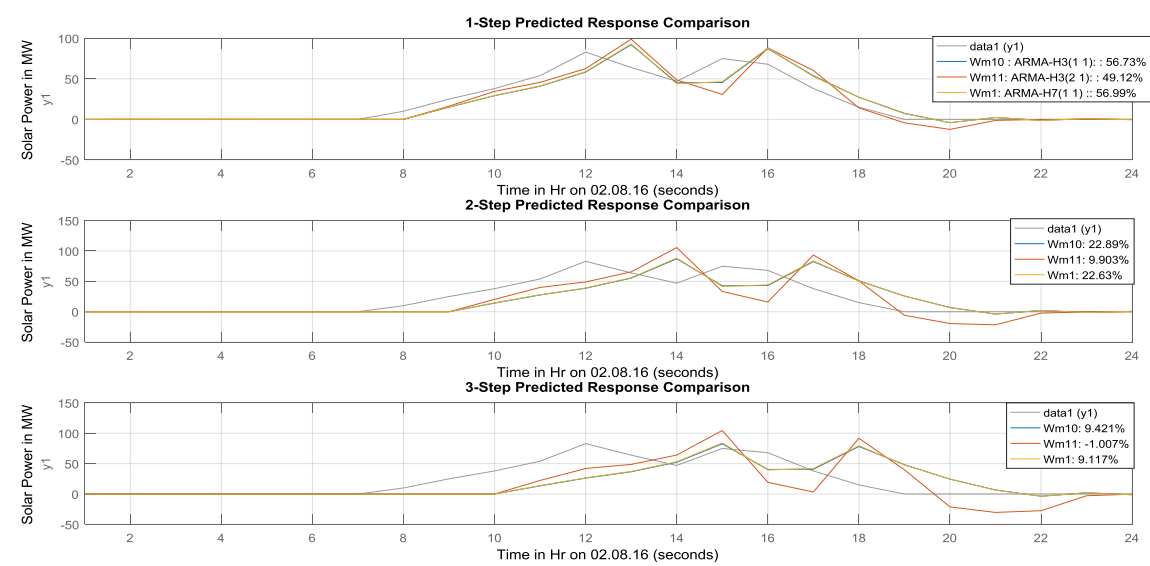

Fig. 8. Solar power generation forecast of ARMA_H-3(1 1), ARMA_H-3(2 1), ARMA_H7(1 1) for different horizons. 
Similarly, the forecast results for solar power generation using hybrid ARMA_H-3(1 1), ARMA_H-3(2 1) and ARMA_H-7(1 1) models for different time horizon are given in Fig. 8 and comparison of forecast results on the basis of different performance parameters is given in Table 3.

Table 3. Comparison of Different ARMA_H and ARMA Models for Solar Power Generation

\begin{tabular}{|llll||}
\hline Model/ Parameters & Fit to Estimation & Forecast Prediction Error & Mean Square Error \\
ARMA(1 24) & $77.60 \%$ & 148.40 & 81.39 \\
ARMA(7 25) & $79.55 \%$ & 137.50 & 67.86 \\
ARMA-H3(1 1) & $72.74 \%$ & 115.70 & 97.89 \\
ARMA-H3(2 1) & $77.47 \%$ & 85.97 & 66.86 \\
ARMA-H7(1 1) & $74.42 \%$ & 117.10 & 99.05 \\
\hline
\end{tabular}

\section{Conclusion}

In this paper, we discussed and designed traditional ARMA(p q) model for solar and wind power generation forecasting using historical data for Maharashtra state of India. The model results are compared for different time horizons and on the basis of defined performance parameters. Further, we have introduced Hybrid ARMA(p q) method for wind and solar power generation forecast and compared their results with ARMA(p q) models. It is observed that the performance of Hybrid model is better as compared to traditional ARMA(p q). Further, it is obseved that for solar generation forecasting; performance of ARMA_H3(2 1) model is better compared to other ARMA and Hybrid ARMA models as value of MSE and FPE is less. Thus it is observed that the performance of the model designed using past three days of historical solar power data is better compared to seven days data. For wind, the performance of ARMA-H7(1 1 ) is better as compared to other ARMA or Hybrid ARMA models because it has lower values of FPE and MSE. Also, wind model designed using historical data for one week is better compared to other models. Further, from model results, it is observed that designed models are most suitable for one step to three steps ahead forecasting - short term solar and wind power generation forecasting.

\section{Acknowledgment}

Prof. Sonali N. Kulkarni is thankful to her friends, colleagues, principal and management of Bharati Vidyapeeth College of Engineering, Navi Mumbai, Maharashtra, India for supporting and encouraging her during this research work.

\section{References}

[1] Ackermann, T. (2005). Wind Power in Power Systems. England: Wiley Publication.

[2] Sandhu, M., \& Thakur, T. (2014). Issues, challenges, causes, impacts and utilization of renewable energy sources - grid integration. International Journal of Engineering Research and Applications, 4(3), 636-643.

[3] Sonali, N., Kulkarni, \& Prashant, S. (2017). Various wind turbine generator systems and their suitability for smart grid integration. International Journal of Advanced Computing and Communication Systems (IJACCS), 3(3), 2347-9280.

[4] Shafiullah, G., Amanullah, M., ShawkatAli, A., \& Wolfs, P. (2013, February). Smart grid for a sustainable future. Smart Grid and Renewable Energy.

[5] Velayutham, A. (2015, January). Expert talk on Power Quality (PQ) Issues in Smart Grid and Renewable Energy Sources. Ex Member, MERC, at SGRES, CPRI, Bangalore. 
[6] Prashant, S. (2016, May 16-21). Recent technology trend in wind energy grid integration. Presented at Workshop on Advances in Power System, VJTI, Mumbai.

[7] Sonali, N., Kulkarni, \& Prashant, S. (2016). A review on power quality challenges in renewable energy grid integration. International Journal of Current Engineering and Technology, 6(5).

[8] Singh, M., Khadkikar, V., Chandra, A., \& Varma, R. (2011, January). Grid interconnection of renewable energy sources at the distribution level with power-quality improvement features. IEEE Transaction on Power Delivery, 26(1).

[9] Arunesh, K., Ibraheem, S., Khatoon, S., \& Muazzam, M. (2013). An overview of electricity demand forecasting techniques. Network and Complex Systems 3(3), 1-11.

[10] George, E. P. B., Gwilym, M. J., \& Gregory, C. R. (1982). Time Series Analysis- Forecasting and Control (4th ed.). New York: Wiley.

[11] Lubosny, Z. (2003). Wind Turbine Operation in Electric Power Systems. Heidelberg, Berlin, Germany: Springer Verlag.

[12] Michael, N., Paras, M., \& Anurag, K. S. (2009). Machine learning applications for load, price and wind power prediction in power systems. Proceedings of the 15th International Conference on Intelligent System Applications to Power Systems.

[13] Sonali, N., Kulkarni, \& Prashant, S. (2016). A review on smart grid architecture and implementation challenges. Proceedings of the International Conference on Electrical, Electronics, and Optimization Techniques (ICEEOT).

[14] Hernandez, L., \& Baladrn, C. (2013). CEER status review of regulatory approaches to smart electricity grids. Council of European Energy Regulators ASBL.

[15] Haida, T. \& Muto, S. (1994). Regression based peak load forecasting using a transformation technique. IEEE Transaction on Power System, 9, 1788-1794.

[16] Eugene, A. F., \& Dora, G. (2005). Applied mathematics for restructured power systems - load forecasting. Springer US, 269-285.

[17] Nima, A., \& Meisam, H. (2006). Energy price forecasting. IEEE Power \& Energy Magazine, 20-29.

[18] Maharashtra state load centre daily report. Retrieved from http://www.mahasldc.in/dailyreport

[19] Chang, W.-Y. (2014). A literature review of wind forecasting methods. Journal of Power and Energy Engineering, 2, 161-168.

[20] Tian, T., \& Ilya, C. (2016, January). Forecasting wind and solar generation: Improving system operations. National Renewable Energy Laboratory, Greening Grid.

[21] Nataraja, C., Gorawar, M. B., Shilpa, G. N., \& Shri, H. J. (2012). Short term load forecasting using time series analysis: A case study for Karnataka, India. International Journal of Engineering Science and Innovative Technology (IJESIT), 1(2), pp.1-9.

[22] Zhang, G. P. (2007). A neural network ensemble method with jittered training data for time series forecasting. Information Sciences, 177, 5329-5346.

[23] Park, H. (1999). Forecasting three-month treasury bills using ARIMA and GARCH Models. Econ 930, Department of Economics, Kansas State University.

[24] Adhikari, R., \& Agrawal, R. K. An introductory study on time series modeling and forecasting. Retrieved from https://arxiv.org/pdf/1302.6613

[25] Chen, H., Canizares, C. A., \& Singh., A. (2001). ANN-based short-term load forecasting in electricity markets. Proceedings of the IEEE Power Engineering Society Transmission and Distribution Conference.

[26] Hamzacebi, C. (2008). Improving artificial neural networks' performance in seasonal time series forecasting. Information Sciences, 178, 4550-4559.

[27] Zhang, G. P. (2003). Time series forecasting using a hybrid ARIMA and neural network model. 
Neurocomputing, 50, 159-175.

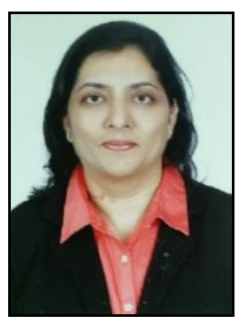

Sonali N. Kulkarni received her B. E. instrumentation, M. E. electronics engineering degree from Shivaji University and University of Mumbai, India respectively. She is an asstistant professor at Bharati Vidyapeeth College of Engineering, University of Mumbai. She is working towards $\mathrm{PhD}$ degree in electronics and telecommunication engineering at Rajiv Gandhi Institute of Technology, University of Mumbai, India. Her current research include issues, challenges in integration of renewable energy sources in smart grid.

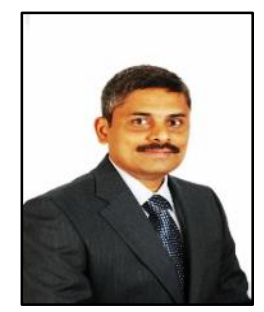

Prashant Shingare received his B.E. instrumentation from Dr. Babasaheb Ambedkar Marathwada University, and $\mathrm{M}$. tech, $\mathrm{PhD}$ in systems \& control engineering from IIT Bombay and MBA in marketing \& finance from Symbiosis International University, Pune, India. He is a certified Project Management Professional (PMP) of PMI USA. He is working as director of renewable energy and heading renewable energy business for Vertiv Energy Pvt Ltd in India. He is an adjunct professor at Rajiv Gandhi Institute of Technology, Mumbai, India where he is PhD supervisor for University of Mumbai. He has published more than 32 research papers in leading journals and conference proceedings. He also serves on boards of leading technical institutes/universities in India and delivered experts talks related to latest technological developments and management practices. He has global and cross functional experience in power, automation, scientific, engineering, technology and EPC organizations. 